Supporting information for

\title{
Design, Synthesis, and Characterization of a Dual Modality PET and Fluorescence Imaging Agent for Monoclonal Antibody Tumor-Targeted Imaging
}

Heng Xu, Kwamena Baidoo, Andrew J. Gunn, C. Andrew Boswell, Diane E. Milenic, Peter L. Choyke, and Martin W. Brechbiel*

\section{Table of Contents}

Table 1. Elemental analysis, Mass and HPLC data of intermediate compounds

Figure 1. HPLC chromatogram of (A) $\mathrm{NH}_{2}$-Lys(SMCC)-CHX-A" 9 and (B) Cy5.5Lys(SMCC)-CHX-A" 3

Figure 2. ES-MS spectra of Cy5.5-Lys(SMCC)-CHX-A” 3 
Table 1. Elemental analysis, Mass and HPLC data of intermediate compounds

\begin{tabular}{|c|c|c|c|c|c|c|c|c|}
\hline \multirow[t]{2}{*}{ Compound } & \multirow[t]{2}{*}{ Chemical Formula } & \multicolumn{4}{|c|}{ Elemental Analysis } & \multirow{2}{*}{\multicolumn{2}{|c|}{$\frac{\text { MASS }}{[\mathrm{M}+\mathrm{H}]^{+} /[\mathrm{M}-\mathrm{H}]^{-}}$}} & \multirow[t]{2}{*}{ HPLC } \\
\hline & & & $\mathrm{C}$ & $\mathrm{H}$ & $\mathrm{N}$ & & & \\
\hline \multirow[t]{2}{*}{ Boc-Lys(Z)-CHX-A" (6) } & \multirow[t]{2}{*}{$\mathrm{C}_{64} \mathrm{H}_{102} \mathrm{~N}_{6} \mathrm{O}_{15} \cdot 0.5 \mathrm{H}_{2} \mathrm{O}$} & Calculated & 63.82 & 8.62 & 6.98 & Calculated & 1195.7481 & \\
\hline & & Found & 63.67 & 8.57 & 6.88 & Found & 1195.7506 & \\
\hline \multirow[t]{2}{*}{ Boc-Lys-CHX-A" (7) } & \multirow[t]{2}{*}{$\mathrm{C}_{56} \mathrm{H}_{96} \mathrm{~N}_{6} \mathrm{O}_{13} \cdot \mathrm{H}_{2} \mathrm{O}$} & Calculated & 62.31 & 9.15 & 7.79 & Calculated & 1061.7114 & \\
\hline & & Found & 62.09 & 9.00 & 8.09 & Found & 1061.7140 & \\
\hline \multirow[t]{2}{*}{ Boc-Lys(SMCC)-CHX-A" (8) } & \multirow{2}{*}{$\mathrm{C}_{68} \mathrm{H}_{109} \mathrm{~N}_{7} \mathrm{O}_{16} \cdot 1.1 \mathrm{H}_{2} \mathrm{O}$} & Calculated & 62.80 & 8.62 & 7.54 & Calculated & 1280.8014 & \\
\hline & & Found & 62.46 & 8.15 & 7.44 & Found & 1280.8040 & \\
\hline \multirow[t]{2}{*}{$\mathrm{NH}_{2}$-Lys(SMCC)-CHX-A" (9) } & \multirow[t]{2}{*}{$\mathrm{C}_{43} \mathrm{H}_{61} \mathrm{~N}_{7} \mathrm{O}_{14}$} & & & & & Calculated & 900.4355 & \multirow{2}{*}{$t_{\mathrm{R}}=25.2 \mathrm{~min}^{2}$} \\
\hline & & & & & & Found & 900.4331 & \\
\hline \multirow[t]{2}{*}{ Cy5.5-Lys(SMCC)-CHX-A"(3) } & \multirow[t]{2}{*}{$\mathrm{C}_{84} \mathrm{H}_{103} \mathrm{~N}_{9} \mathrm{O}_{27} \mathrm{~S}_{4}$} & & & & & Calculated & 1796.6 & \multirow[t]{2}{*}{$t_{\mathrm{R}}=18.5 \mathrm{~min}^{b}$} \\
\hline & & & & & & Found & 1797.6 & \\
\hline
\end{tabular}

${ }^{a}$ HPLC data was acquired by using a Vydac Protein \& Peptide reversed-phase $\mathrm{C}_{18} 10 \mathrm{~mm}$ $\times 25 \mathrm{~cm}$ column equilibrated with $0.1 \%$ TFA in $\mathrm{H}_{2} \mathrm{O}(\mathrm{v} / \mathrm{v})$. A 0.0 to $60 \%$ gradient of increasing $\mathrm{CH}_{3} \mathrm{CN}$ over $35 \mathrm{~min}$ at a flow rate of $2 \mathrm{ml} / \mathrm{min}$ was employed and the chromatogram is presented in Figure 1A.

${ }^{b}$ HPLC data was acquired by using a Vydac Protein \& Peptide reversed-phase $\mathrm{C}_{18} 10 \mathrm{~mm}$ $\times 25 \mathrm{~cm}$ column equilibrated with $0.015 \mathrm{M} \mathrm{NH}_{4} \mathrm{OAc}$. A 0.0 to $50 \%$ gradient of increasing $\mathrm{CH}_{3} \mathrm{CN}$ over $30 \mathrm{~min}$ at a flow rate of $3 \mathrm{ml} / \mathrm{min}$ was employed and the chromatogram is presented in Figure 1B. 
Figure 1. HPLC chromatogram of (A) $\mathrm{NH}_{2}$-Lys(SMCC)-CHX-A" 9 and (B) Cy5.5-

\section{Lys(SMCC)-CHX-A" 3}

A)
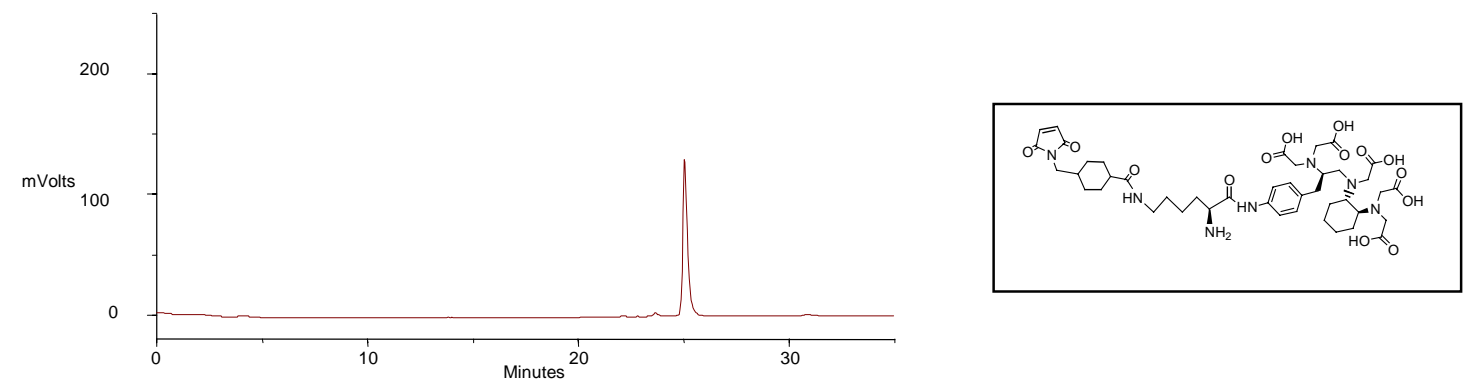

B)
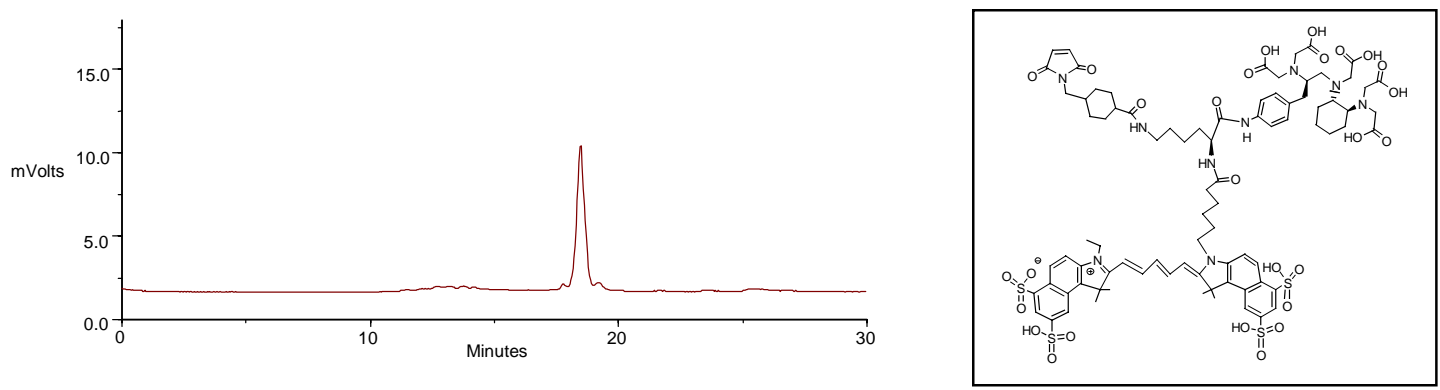
Figure 2. ES-MS spectra of Cy5.5-Lys(SMCC)-CHX-A" 3

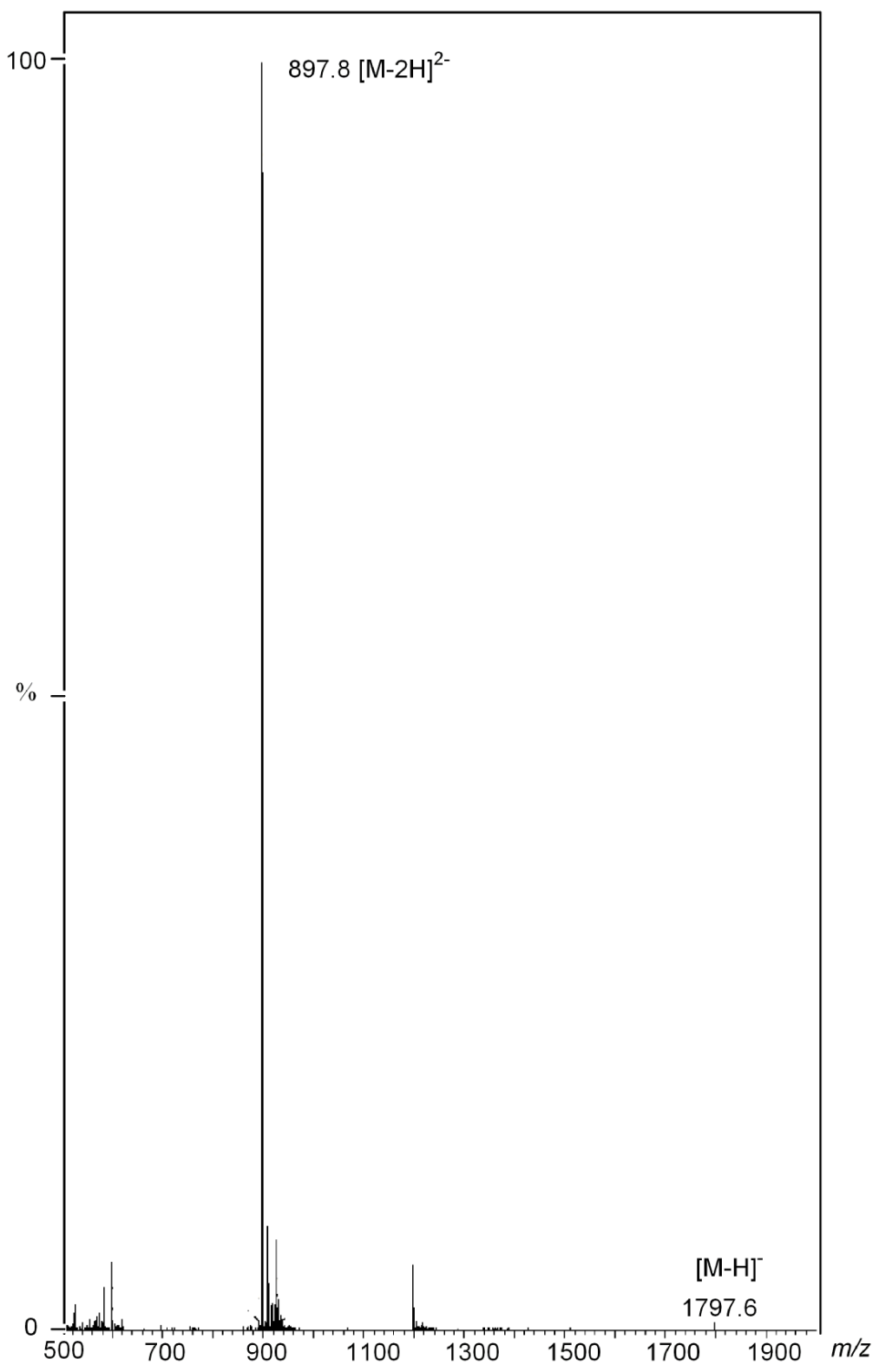

